\title{
Correction to: Interventions to improve vaccine acceptance among rheumatoid arthritis patients: a systematic review
}

\author{
Vincent Gosselin Boucher ${ }^{1,2} \cdot$ Ines Colmegna ${ }^{3}$. Claudia Gemme ${ }^{1,2}$. Sara Labbe ${ }^{1,2}$. \\ Sandra Pelaez ${ }^{4} \cdot$ Kim L. Lavoie ${ }^{1,2}$
}

Published online: 27 February 2019

(C) International League of Associations for Rheumatology (ILAR) 2019

\section{Correction to: Clinical Rheumatology https://doi.org/10.1007/s10067-019-04430-7}

The original version of this article contained error. Table 1 was shown in the wrong version, thus corrected table is shown in this article. The original article has been corrected.

Publisher's note Springer Nature remains neutral with regard to jurisdictional claims in published maps and institutional affiliations.

The online version of the original article can be found at https://doi.org/ 10.1007/s10067-019-04430-7

Kim L. Lavoie

kiml_lavoie@yahoo.ca

1 Department of Psychology, University of Quebec at Montreal (UQAM), CP 8888, Sucursale Centre-Ville, Montreal, Quebec H3C 3P8, Canada

2 Montreal Behavioural Medicine Centre, Centre Intégré Universitaire de santé et services sociaux du Nord-de-l'Ile-de-Montréal (CIUSSS-NIM), Hôpital du Sacré-Coeur de Montréal Canada, Montréae, Canada

3 Department of Medicine, Division of Rheumatology, McGill University, Montreal, Canada

4 Department of Educational and Counselling Psychology, McGill University, Montreal, Canada 


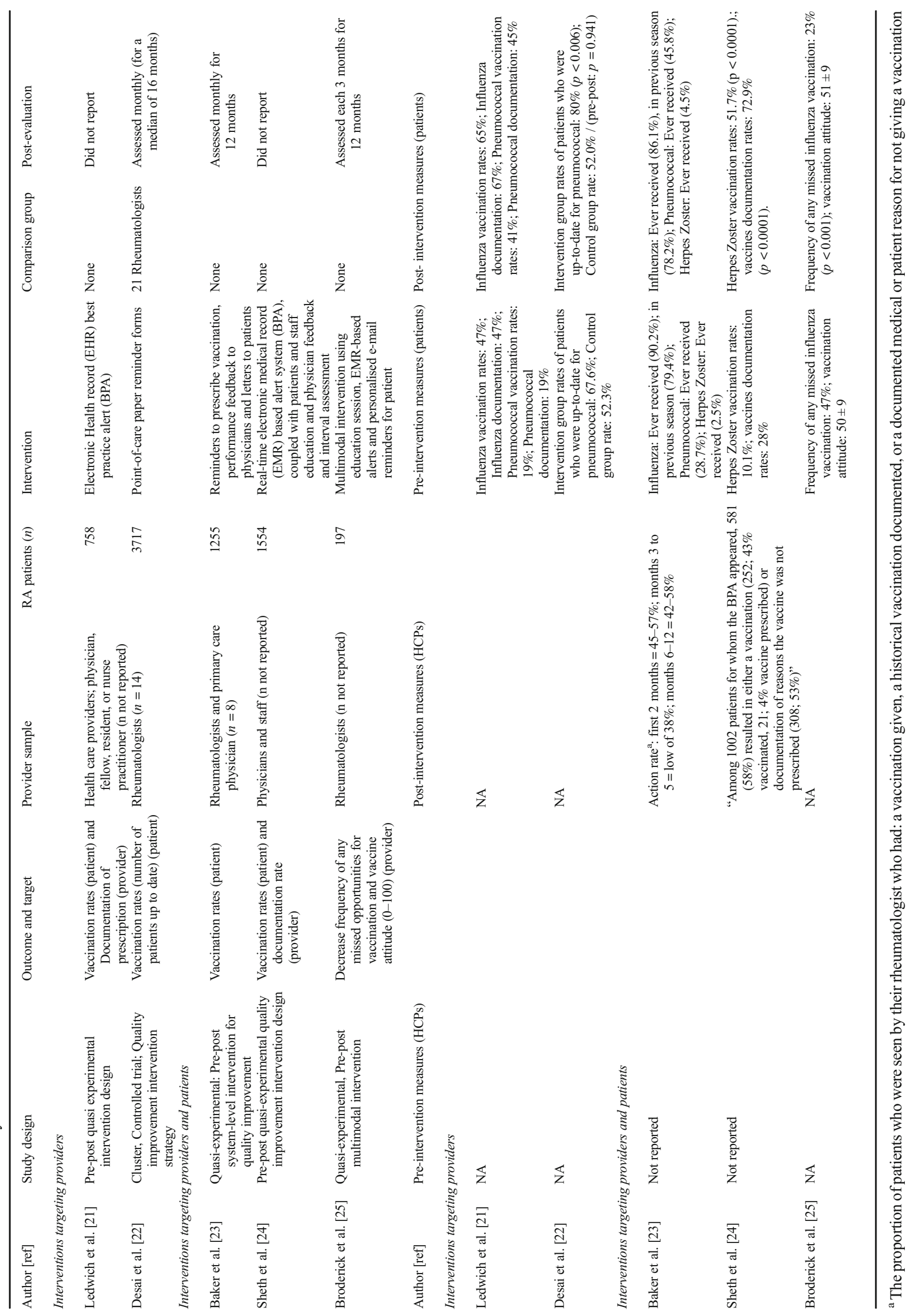

